ISG Prepared for the Seminar on Decision-making regarding abortion-determinants and consequences, organized by the IUSSP Scientific Panel on Abortion Research in collaboration with the Strengthening Evidence for Programming on Unintended Pregnancy (STEP UP) Research Consortium, in Nanyuki, Kenya, 3-5 June 2014.

\title{
Pregnancy termination trajectories in Zambia
}

\author{
Dr Ernestina Coast \\ London School of Economics \\ Dr Susan Murray \\ King's College London
}

Acknowledgements:

The funding for this research was provided by ESRC/DFID [ES-167-25-0626]. Research assistance by Erica Chifumpu, Victoria Saina, Taza Mwense, Doreen George, Sr Hilda and Sr Scolastica. Review of, and revisions to, this paper by Dr Emily Freeman. Other team members involved in the design and collection of instruments, and preliminary discussions about findings: Dr Bellington Vwalika, Dr Tiziana Leone, Dr Divya Parmar, Dr Bornwell Sikateyo, Dr Eleanor Hukin and Dr Emily Freeman. To University Teaching Hospital, Lusaka, for permission to conduct this research. Manuscript and IUSSP presentation prepared with help from Dr Emily Freeman (London School of Economics). Most importantly, to the girls and women who talked to us about their experiences.

Date of last revision: (July 2014)

\section{DO NOT CITE WITHOUT AUTHORS' PERMISSION}




\begin{abstract}
Unsafe abortion is a significant, but preventable cause of maternal mortality in Zambia. We compared the trajectories of women seeking safe abortion with those receiving care following unsafe abortion. We interviewed women $(n=112)$ accessing care in a large government hospital about their experiences. The study captured a third termination trajectory in which women received medical abortion outside the study hospital from qualified (legal) and unqualified providers. The advice of others, perceptions of risk, economic cost and delays in care seeking and receipt all influenced which trajectory a woman followed, as well as the complexity and timing of her trajectory.
\end{abstract}

\title{
CONTEXT AND RATIONALE
}

Unsafe abortion is a significant, but preventable, cause of maternal mortality. Zambia's adjusted $^{1}$ maternal mortality ratio is estimated to be 280 [170-460] deaths per 100,000 live births in 2013 (WHO, UNICEF et al. 2013), of which a significant proportion (30\%) (GRZ 2009) are likely to be due to unsafe abortion, although there are no nationally representative data available. In addition, unsafe abortion is a significant cause of morbidity among women and girls and is both a cause and a consequence of poverty.

Induced abortion is more likely when unmet need for effective contraception is high. Pregnancies reported as unplanned are common in Zambia, with $16 \%$ of birth reported as unwanted, and $26 \%$ reported as mistimed. Unmet need for effective contraception among married Zambian women (an underestimate of the unmet need for women overall) is $27 \%$, and it is estimated that if all married women with an unmet need for contraception were to use a method, the Zambian contraceptive prevalence rate would rise to $67 \%$ from $41 \%$ (Central Statistics Office, Ministry of Health et al. 2009).

\section{Zambia's legal and policy context}

Unsafe induced abortion is more likely when procedures are clandestine and legal provision is restrictive (Grimes, Benson et al. 2006). However Zambia has one of the most liberal abortion policies in sub-Saharan Africa (Table 1).

\footnotetext{
${ }^{1}$ Adjusted to remove HIV/AIDS related deaths
} 


\author{
Table 1: legality of abortion, by African country (2012) [Zambia highlighted] \\ Reason \\ Countries \\ Prohibited altogether, or no \\ explicit legal exception except \\ to save the life of a woman \\ Angola, CAR, Congo (Brazzaville), DRC, Egypt, Gabon, Guinea-Bissau, \\ Lesotho, Madagascar, Mauritania, mautirius, Sao Tome and Principe, \\ Senegal, Somalia \\ To save the life of a woman \\ To preserve physical health \\ (and to save a woman's life)* \\ Cote d'Ivoire, Libya (e), Malawi (f), Mali (a, b), Nigeria, Sudan (a), Tanzania, \\ Uganda \\ Benin ( $a, b, c)$, Burkina Faso ( $a, b, c)$, Burundi, Cameroon (a), Chad (c), \\ Comoros, Djibouti, Equiatorial Guine (e, f), Eritrea (a, b), Ethiopia (a, b, c, \\ d), Guinea (a, b, c), Kenya, Morocco (f), Mozambique, Niger (c) Rwanda, \\ Togo (a, b, c), Zimbabwe (a, b, c) \\ To preserve mental health (and Algeria, Botswana (a, b, c), Gambia, Ghana a, b, c), Liberia (a, b, c), \\ all of the above reasons) \\ Namibia $(a, b, c)$, Seychelles $(a, b, c)$, Sierra Leone, Swaziland $(a, b, c)$ \\ Zambia (c) \\ Socioeconomic grounds (and all \\ of the above reasons) \\ Without restriction as to reason Cape Verde, South Africa, Tunisia \\ *Includes countries with laws that refer simply to "health" or "therapeutic" indications, which may be \\ interpreted more broadly than physical health. Notes: Some countries also allow abortion in cases of (a) rape, \\ (b) incest, (c) fetal impairment or (d) other grounds. Some restrict abortion by requiring (e) parental or (f) \\ spousal authorization. Countries that allow abortion on socioeconomic grounds or without restriction as to \\ reason have gestational age limits (generally the first trimester); abortions may be permissible after the \\ specified gestational age, but only on prescribed grounds.
}

Source (Guttmacher Institute 2012)

The Termination of Pregnancy Act, enacted in 1972 (Chapter 304 of the Laws of Zambia) and amended in 1994 (GRZ 2009), legalises induced abortion when the continuation of pregnancy would involve: "(i) risk to the life of the pregnant woman; or(ii) risk of injury to the physical or mental health of the pregnant woman; or(iii) risk of injury to the physical or mental health of any existing children of the pregnant woman, greater than if the pregnancy were terminated; or(b) that there is a substantial that if the child were born it would suffer from such physical or mental abnormalities as to be seriously handicapped". In determining whether the continuity of pregnancy would involve these risks, practitioners may take account "of the pregnant woman's actual or reasonably foreseeable environment or of her age" (GRZ 1972 Section 3.1-3.2). In addition a 2005 amendment, brought about due to a concern with increasing rates of gender based violence (GRZ 2009), makes further provision for termination of pregnancy resulting from rape or defilement of children (Act No. 15 of 2005, Section 152[2]).

The Penal Code (Chapter 87 of the Laws of Zambia) itself criminalises unsafe and illegal terminations [Sections 151 to 153]. Adults who obtain an illegal, unsafe abortion risk fourteen years' imprisonment, while any person unlawfully administering means to procure the termination of a woman or child's pregnancy risk seven years' imprisonment.

Zambia has been a signatory to CEDAW (Convention on the Elimination of all forms of Discrimination Against Women) since 17 Jul 1980, and ratified this treaty on 21 Jun 1985 (UNTC 2013). In 2000 a Post Abortion Task Force was established that led to the publication of national Standards and Guidelines for reducing morbidity and mortality from unsafe abortion $\{\mathrm{MoH}, 2009$ \#264\}. In 2003 Zambia ratified the Maputo Protocol, the international treaty which outlines obligations for States to provide comprehensive reproductive health care, including abortion (Migiro 2013). 
Despite comprehensive legal provision for safe abortion, and significant legal deterrents for unsafe abortion, prevalence of unsafe abortion remains considerable. For every woman having a safe abortion in 2000-2008, it was estimated that 85 women were admitted to hospitals with abortion-related complications (including complications from spontaneous abortions), accounting for just over one third of all gynaecologic admissions (Likwa 2009). The capital city, Lusaka, has the best gynaecology provision in the country, but of women attending the Gynaecological Emergency Admission Ward of a tertiary hospital in Zambia for abortion-related care, just $20 \%$ attend for safe abortion (SA) services, and $80 \%$ require post abortion care many of these following unsafe procedures carried out elsewhere (Kaseba, Pers. Comm.). On the basis of a community-based study in western Zambia, it was estimated that one in one hundred girls of school age dies from abortion-related complications each year (Koster-Oyekan 1998).

Why women and girls in Zambia continue to risk their health (and their freedom) to terminate their pregnancies using unsafe methods is therefore an important question for public health. The Zambian government has expressed concern about the continuing high incidence of unsafe abortion in Zambia, but efforts to reduce these have so far had little effect (Likwa, Biddlecom et al. 2009). One argument is that despite a favourable legal framework, administrative and service constraints limit access to safe abortion (Kaseba, Phiri et al. 1998, Mtonga and Ndhlovu 2001). The Termination of Pregnancy Act (1972) states that except in cases of medical emergency, three practitioners are required to sign their consent for the termination, one of whom must be a specialist in the branch of medicine relating to the case. Further, terminations must be carried out in hospitals, and conducted by a registered medical practitioner. However access to hospitals registered to perform abortions is difficult in parts of the country, especially in rural areas.

A second argument is that there is low awareness of the availability of safe abortion. The CEDAW committee, who have criticised the Government for Zambia's high rates of maternal mortality and morbidity resulting from unsafe abortions, recommended both an awareness raising campaign regarding the legality of abortion and improved provision of care for complications from unsafe abortion (UN and CEDAW 2011). Public awareness and acceptance of legal safe abortion is reflected in on-going debates about the implications for abortion of a draft amendment to the Constitution of Zambia that stated: "(1) A person has, subject to clauses (2) and (3), the right to life, which begins at conception, and (2) A person shall not be deprived of life intentionally, except to the extent authorised by this Constitution or any other law." (TCDZC 2012):14). While some commentators have suggested that such a change in definition of the beginning of life would undermine the legality of abortion, other have argued that provision for the law as set out in the Termination of Pregnancy Act (1972) is given in the final clause of the revision (Kalunga 2012, Chakwe 2013, Concerned 2014).

This paper sets out to contribute understanding of why the public sector investment in safe abortion services in Zambia is not fully used by women seeking to terminate a pregnancy. It does so by comparing the trajectories of individuals seeking induced abortion within a hospital environment with the trajectories of those receiving abortion-related care there following a termination initiated elsewhere. The focus of the paper is therefore on the pathways to those terminations. 
The study focuses on Zambia, although similar patterns of continued high levels of unsafe abortions following legislative change have been noted elsewhere. For example, Ethiopia significantly expanded the potential for safe and legal abortion in 2006 but a national study conducted in 2008 shows that only $27 \%$ of induced abortions were safe and conducted in health facilities (Singh, Fetters et al. 2010). Research in Zambia may therefore have broader lessons for developments elsewhere in the region.

The study location of Lusaka offers the optimal in current scenarios - it has a typical urban concentration of gynaecologists and established abortion services in government facilities. Yet despite this we know that significant numbers of women seeking to terminate their pregnancy do not go directly to these services, that some still resort to unsafe practices, and that some subsequently access Lusaka's government facilities for post-abortion care.

\section{LITERATURE REVIEW}

This study is situated in a regional context where data on abortion in sub-Saharan Africa are known to be "rare and non-representative" (Rossier and et al. 2006) and difficult to collect. Much of current understanding therefore comes from larger hospital-based studies. These studies have used hospital records to provide contextual information on the characteristics of women limited to broad socio-demographic information (for example, age, schooling and parity) ( Baboo, Ahmed et al. 1994, Likwa and Wittaker 1996, Dahlback, Maimbolwa et al. 2007). They typically they do not deal with routes to, or reasons for, seeking care.

Some small-scale ethnographic studies on issues surrounding abortion in Zambia exist that provide useful contextual information. Koster-Oyekan's (1998) study in Western Province investigated why women seek illegal abortions while Castle et al.'s (1990) study presents observations of the barriers faced by women attending a gynaecology emergency ward in Lusaka in 1988. Webb's (2000) and Sims' (1996) studies present perceptions of common reasons for terminating pregnancies and methods used to self-induce (unsafe) abortions. These studies identified socially-embedded reasons for pregnancy termination (including schooling and protection of the wellbeing of existing children) and inaccessibility and unacceptability of legal abortion services. However no studies have focused on the perspectives of women who have terminated their pregnancy safely and legally and compared these to the perspectives of women who have accessed unsafe and illegal abortion services.

We know relatively little about the pathways - which can be long and difficult or can be short and direct - for women to reach providers of pregnancy termination services and care in any African settings (Schwandt, Creanga et al. 2013). Studies that seek to understand pathways to treatment for other health services can be helpful in contributing to an understanding of women's pathways to pregnancy termination. For example, evidence from India shows that the treatment seeking behaviour of TB patients that reach DOTS services can be protracted (with multiple delays) and complex, involving a complex mix informal, regulated private and public providers (Kapoor, Raman et al. 2012). Similar pathways and trajectories have been noted for HIV diagnosis and treatment. These situations may have some relevance to pregnancy termination trajectories because of the impact of stigma on decision-making. However pregnancy termination trajectories can be 
considered a distinct group of healthcare seeking behaviours because - unlike many other forms of healthcare - the issues of legality and understanding of legal rights overlay an individual's journey to achieving care.

A study in India, where TOP is legal, shows that women's trajectories often began with social networks of friends/relatives and then progress to (un)qualified medical providers (Banerjee and Andersen 2012). More than half (53\%) of the women studied began to selfinduce at home. A similar, earlier study in Bangladesh, showed very similar patterns, with many women seeking care from 2 or 3 providers in order to procure a ToP (Ahmed, Islam et al. 1999). Having accessed a provider, choice method of termination can also be complex. In Mozambique women seeking an abortion were offered a choice of regimes (Misoprostol for a medical abortion (Miso) or a surgical abortion using manual or vacuum aspiration (MVA)) and interviewed about the reasons for their choice. Privacy, perception of pain, quality of home support, HIV infection risk, level of invasiveness and concerns about safety of research participation ${ }^{2}$ were all found to shape women's decisions (Mitchell, Kwizera et al. 2010). In this study women were highly motivated to identify and use low risk (socially and clinically) termination methods, and both miso and miso+MVA were important choices.

\footnotetext{
${ }^{2}$ Participation in the study for women taking misoprostol at home involved observing expulsion and recording their symptoms. Most women (95.2\%) were comfortable both observing and describing the process, although a minority found it emotionally challenging.
} 


\section{RESEARCH METHODS}

This study builds on established rigorous approaches to the study of abortion using a hospital-based approach to recruitment of women for in-depth interviews (Kinaro, Ali et al. 2009), but significantly extends and develops these by incorporating clinical (record audit), and microeconomic data. We need to understand why some women are able to access safe abortion services and others are not in this context. It is reasonable to expect that there are social, financial, and institutional reasons for this, and a mixed methods analysis drawing on different disciplinary perspectives is likely to be the best means to develop a nuanced understanding. The larger study from which the data for this paper are drawn is multidisciplinary (health economics, policy analysis, sociology, anthropological demography, medical practitioner, statistics) and incorporates primary data collection of both qualitative and quantitative data.

The research strategy was one of a comparative case study comparing women seeking safe abortion (SA) with women seeking abortion-related care having initiated an induced abortion elsewhere. It balances the need to assemble detailed understandings of individual contexts and complexities against the necessity of producing some level of generalisation (Rihoux and Grimm 2006). Primary data collection was essential in order to address these questions and produce the evidence needed to inform policymaking in Zambia. The most recent Zambian Demographic and Health Survey (ZDHS) does not distinguish between miscarriage and induced termination in its question on pregnancy termination, making it unsuitable for secondary analyses. The research process was designed to be iterative and interpretative, with a continuous interplay between data collection and analysis. Independent ethical review was granted by the London School of Economics and the University of Zambia Research Ethics Committees.

Following a pilot study in 2012, women and girls ( $n=112)$ seeking termination of pregnancy or abortion-related care at a hospital in Zambia were interviewed. The research used an innovative mixed methods interview which combined quantitative and qualitative techniques in one interview. Each participant was interviewed by two interviewers. One interviewer led the interview, using a conventional interview schedule in the manner of a qualitative semi-structured interview to encourage the woman to tell her story, while the second interviewer listened and, where possible, completed a quantitative 'data sheet'. When the first interviewer has completed the qualitative part of the interview, interviewer two took over and asked the participant closed-questions used to establish the sociodemographic characteristics of girls and women using hospital-based SA and abortionrelated care services and the financial costs of abortion-related care.

This technique allowed us to capture both the individual fine-grained narratives, which are not easily captured in a questionnaire-type survey, especially on such a sensitive topic, as well as survey data. Rather than conducting an in-depth qualitative interview and a survey, our method reduced the burden on the respondent, avoiding repetition of questions and reducing the time taken. This paper presents the results of our analyses of qualitative data generated. 
Each participant was asked to document their informed consent to participate before being interviewed using a signature or thumbprint. All by two participants gave permission for the interview to be audio-recorded. For these interviews the second interviewer took handwritten verbatim notes during the interview. Immediately after each interview the two interviewers reviewed the data sheet (and any notes if not audio-recorded) and wrote a 300 word summary ("vignette") including whatever information or impressions they considered to be most pertinent from the interview. Interviews were conducted in a private room within the hospital, in the language of the interviewee's choice ${ }^{3}$. After each interview interviewer one transcribed and simultaneously translated the audio-recording to English. During pilot testing it was decided that conducting the interview on the ward - in the sisterin-charge's office - would make participants feel more comfortable and at ease to speak than if they were interviewed off the ward, so this became the main room for interviewing. Interviews were conducted privately with women prior to discharge and after any prescriptions etc. had been given.

Over a 12 month period, all women identified as having undergone either a safe induced abortion at the study hospital or having received abortion-related care there following an attempted induced abortion elsewhere were approached for inclusion in the study. We did not interview women identified as having received abortion-related care following a spontaneous abortion. Undoubtedly, some women claiming to have had a spontaneous abortion had in fact attempted to induce an abortion, and at times medical evidence suggested so, however we could not interview them about the attempt as they were not willing to disclose any information on an attempted induced abortion. Two senior nurses working on the obstetrics and gynaecology ward identified suitable women for recruitment and asked them if they would be willing to participate in the study.

\section{Qualitative analyses}

Preliminary content analysis of purposively selected transcripts $(n=20)$ was carried out by the authors and the Lusaka-based research assistants and discussed in a team analysis workshop. The preliminary sub-sample maximized for heterogeneity in sociodemographic characteristics, including: age, marital status, ethnic group, education, employment status, residence, in financial circumstances, and in clinical intervention and outcomes. This preliminary content analysis informed the subsequent framework analyses, conducted by the authors, reported here. Framework Analysis, or 'Framework' (Ritchie and Lewis 2003 p.219-20), is a method for systematically categorising, organising and synthesising case oriented qualitative data. It is a matrix based analytical approach to thematic analysis in which a framework is used to re-arrange data by key themes and by case in order to facilitate both within and across case descriptive and explanatory analysis. In our analyses, this involved immersion of the analyst in all of the data to ensure that we have a sense of each case in its entirety (for example, each interview transcript, vignette, quantitative data, and medical notes) and the diversity presented in the data. From this, key recurring themes and related sub-themes were identified and mapped to ensure there is conceptual clarity within them, with no obvious omissions or overlaps between them. In our analyses the themes were shaped by the analytical ideas that emerged from the preliminary team content analyses, meaning that a combination of deductive and inductive themes were included (Gale, Heath et al. 2013).

\footnotetext{
${ }^{3}$ English (48\%), Bemba (7\%) and Nyanja (60\%)
} 
We developed each theme in a separate matrix, in which each related sub-theme was allocated a column and each case was allocated a row. We included analytic comments in our matrices in order to create a log of all our interpretive observations and reflections that were separate from the data. The matrices contained participants' recorded words and phrases and retain information about the context in which they were expressed, as well as a reference to the raw data (paragraph number in the interview transcript), creating a transparent audit trail of the analytical process (Ward, Furber et al. 2013 p.2428). The charting of data within a matrix highlights the complexities within each case, encouraging thick description (Gale, Heath et al. 2013); the visual display of the matrix itself encourages a display of diversity in data and thus avoidance of bias (Ritchie and Lewis 2003, Gale, Heath et al. 2013), while presence of empty cells within the matrix makes it easy to check whether there is sufficient evidence for proposed themes and concepts (Gale, Heath et al. 2013); and the audit trail created by each step of the analytical process increases dependability (Ward, Furber et al. 2013) and makes the method particularly useful for teamwork, especially when working remotely (Ritchie and Lewis 2003, Dixon-Woods 2011).

\section{SAMPLE DESCRIPTION}

The hospital-based recruitment strategy yielded a heterogeneous sample of girls and women, from a 15 year old schoolgirl who had never used contraception, to a 23 year old unmarried university student who did not want an unplanned pregnancy to interrupt her studies, to a 42 year old married mother of 6 children reporting contraceptive failure and an inability to support another child (Table 2 ).

Table 2: Percentage distribution of sample socio-demographic characteristics

\begin{tabular}{|c|c|}
\hline Characteristics & Percent distribution $(n=112)$ \\
\hline \multicolumn{2}{|l|}{ Age group (range $15-43$ years) } \\
\hline $15-19$ & 25.0 \\
\hline $29-24$ & 27.9 \\
\hline $25-29$ & 14.4 \\
\hline $30-34$ & 17.3 \\
\hline$>35$ & 13.5 \\
\hline \multicolumn{2}{|l|}{ Highest school level completed } \\
\hline Nursery/kindergarten & 12.5 \\
\hline Primary & 34.6 \\
\hline Secondary & 33.7 \\
\hline higher & 16.3 \\
\hline \multicolumn{2}{|l|}{ Religion } \\
\hline Catholic & 27.9 \\
\hline Protestant & 9.6 \\
\hline Muslim & 1.0 \\
\hline Seventh Day Adventist & 14.5 \\
\hline Other & 45.3 \\
\hline \multicolumn{2}{|l|}{ Main occupation / activity } \\
\hline Work for pay (f-t / p-t) & 25.9 \\
\hline Housewife & 10.6 \\
\hline Student & 25.9 \\
\hline Runs own business & 17.3 \\
\hline Unemployed and seeking work & 5.8 \\
\hline
\end{tabular}




\begin{tabular}{|c|c|}
\hline \multicolumn{2}{|l|}{ Current marital status } \\
\hline Widowed & 2.9 \\
\hline Divorced & 3.8 \\
\hline Separated & 2.9 \\
\hline Never-married & 75.0 \\
\hline Using contraception at the time of most recent pregnancy & $\mathbf{5 1 . 0}$ \\
\hline
\end{tabular}

Note: $\%$ do not add up to $100 \%$ due to variable item non-response

Approximately half (51\%) of respondents reported that they were using some form of contraception when they became pregnant, and these respondents tended to be married women and mothers (CASE\#1, \#2). By contrast younger women, especially adolescents (1519 years), were much less likely to have been using contraception when they became pregnant (57.7\% not using any contraception at the time of the pregnancy).

\section{FINDINGS}

\section{A typology of trajectories}

Initially our research study was designed to be a comparison between women who had used 'safe' and 'unsafe' termination of pregnancy. However, analyses of the data revealed a triad of categories, which did not neatly fit into a simple safe/unsafe dichotomy. A substantial proportion of girls and women recruited into our study had initiated a ToP prior to arriving at the hospital for abortion-related care, and some of these had resorted to dangerous or ineffective methods. However, in this group, a significant proportion appeared to have initiated a ToP using medical abortion methods obtained from another source. This finding corroborates Ganatra et al.'s recent comments on WHO's definition of unsafe abortion and their suggestion that with the changing availability of medical abortion methods safety needs to be understood as a continuum, with a "spectrum of risk" (Ganatra, O. et al. 2014).

Based on our analyses, we develop a typology of three, mutually exclusive, ToP trajectories in this group of women who received public sector hospital care: 


\section{Typology 1: $\quad$ Clinical $^{4}$ ToP procured at tertiary government hospital}

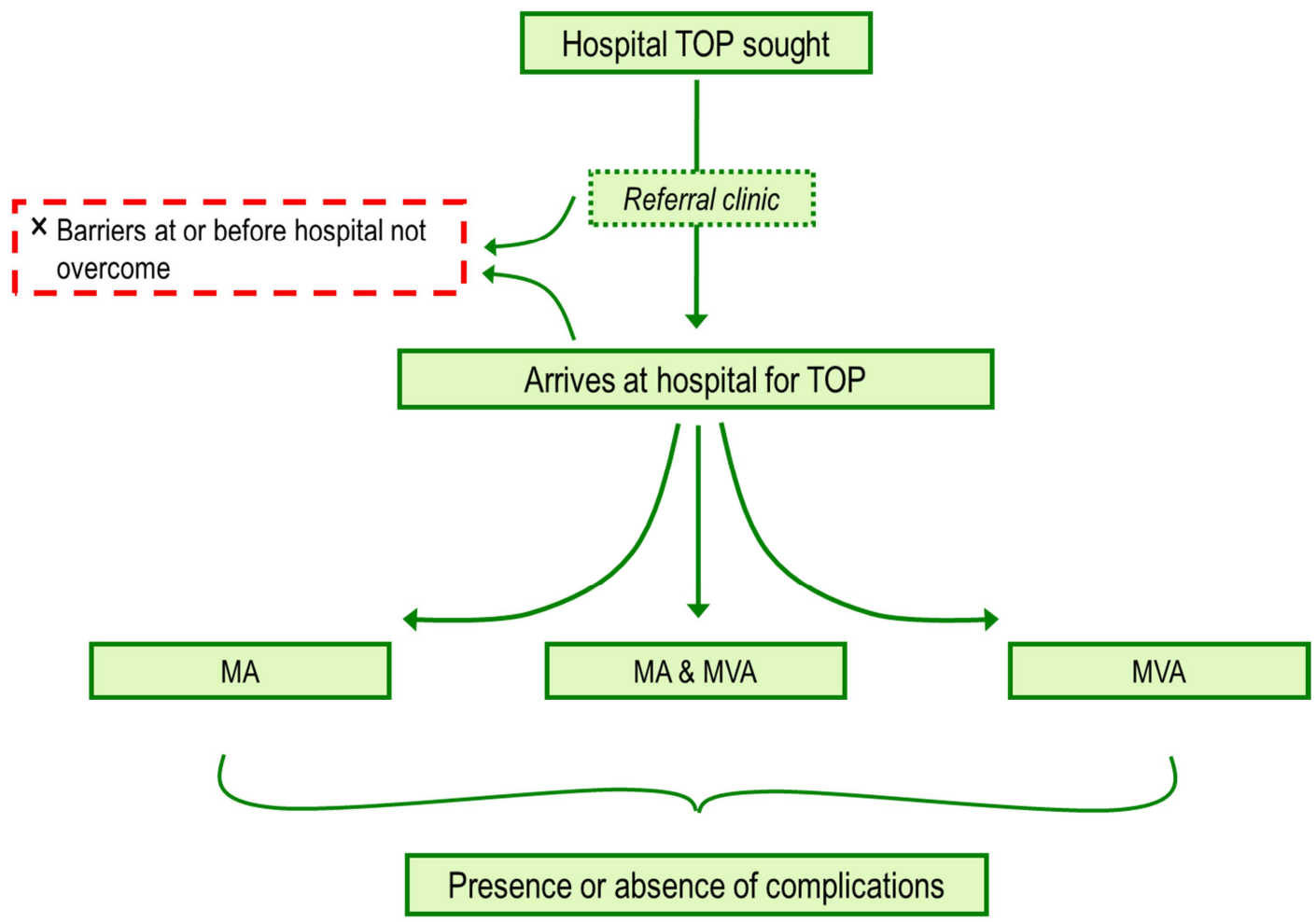

Typology 2: $\quad$ Clinical $^{13}$ ToP undertaken elsewhere, followed by abortion-related care at tertiary government hospital

I

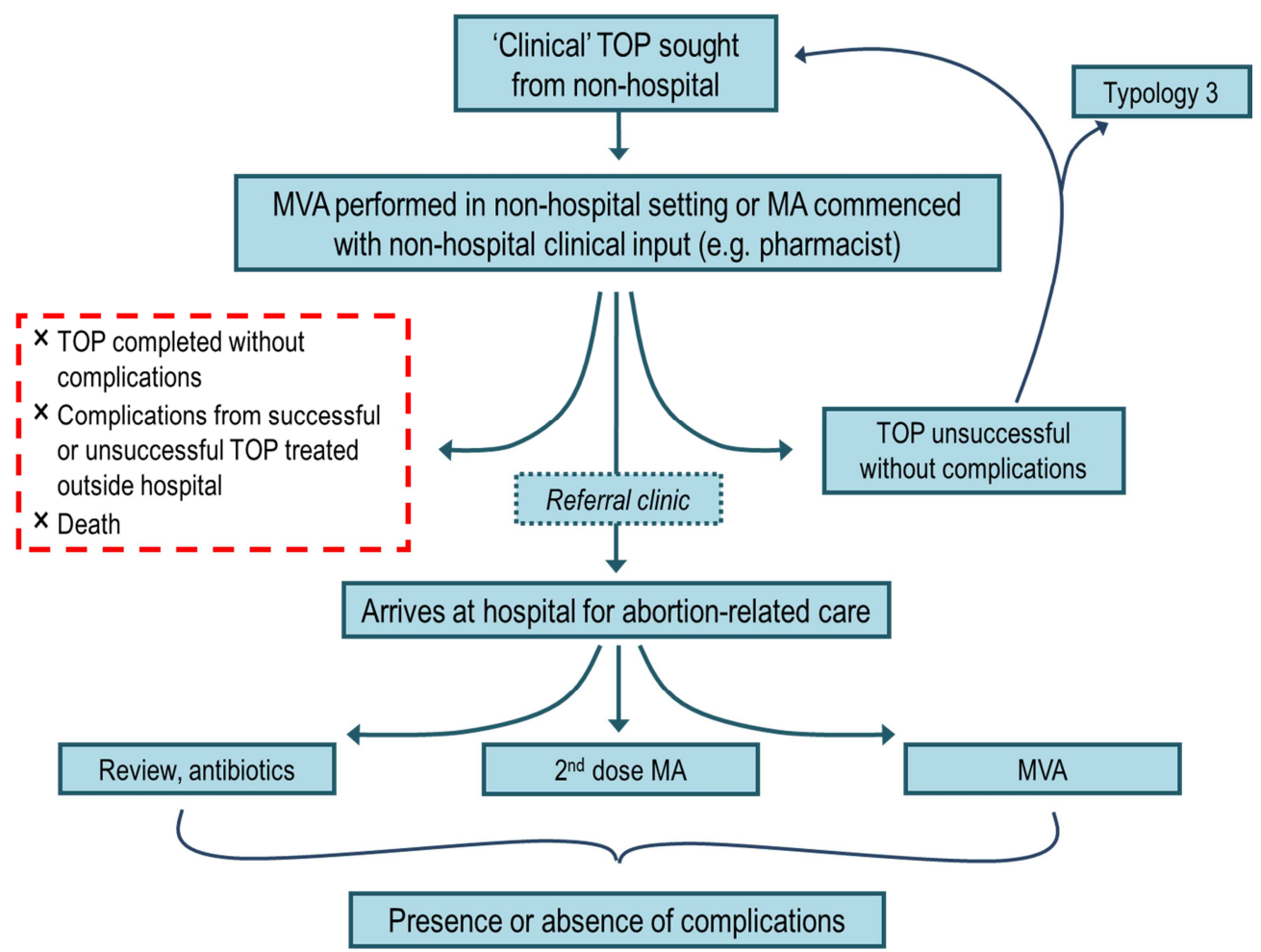

\footnotetext{
${ }^{4} \mathrm{MA} / \mathrm{MA}+\mathrm{MVA} / \mathrm{MVA}$
} 


\section{Typology 3: Non-clinical ${ }^{5}$ ToP sought, followed by abortion-related care at tertiary government hospital}

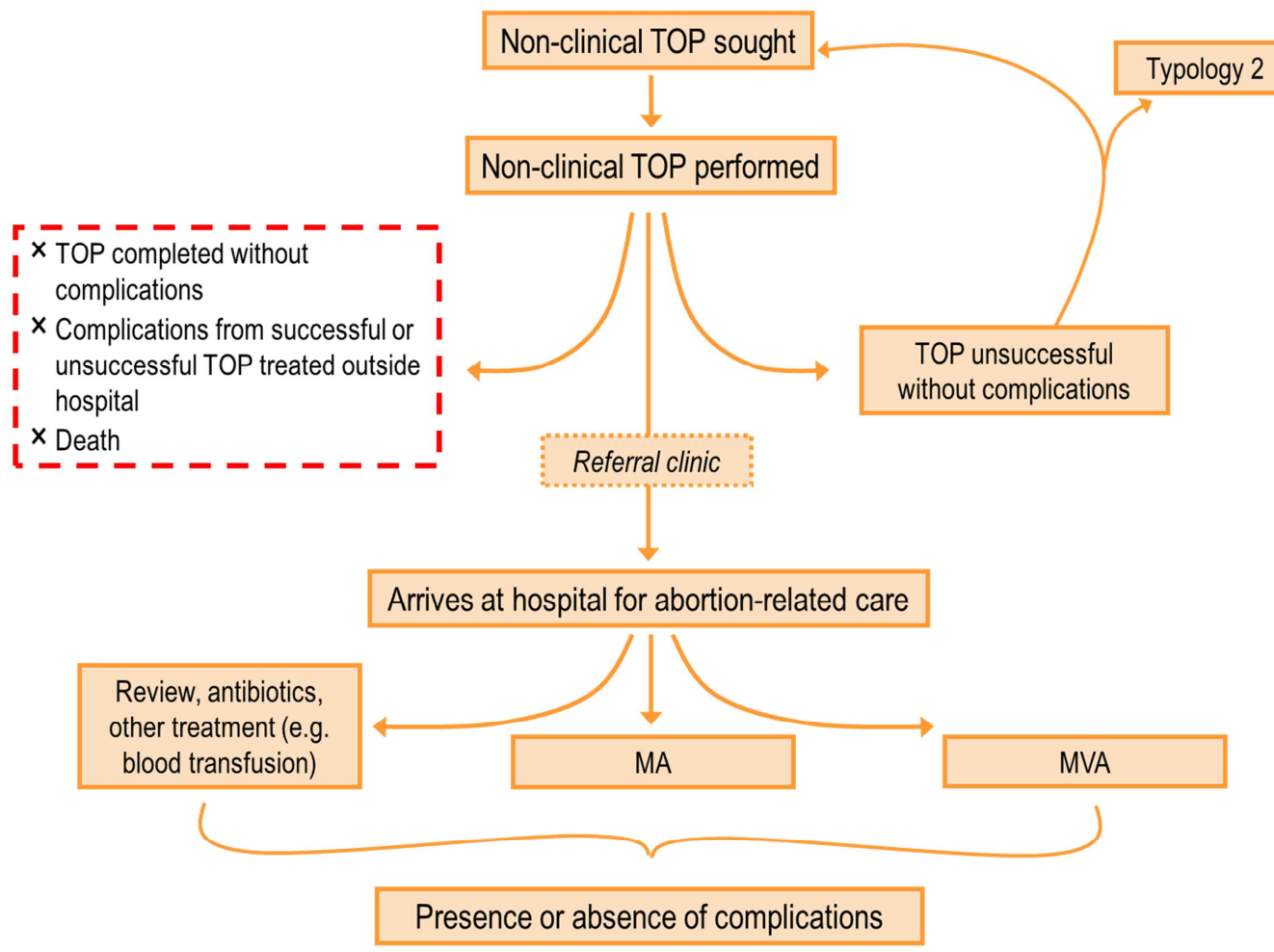

These trajectories reflect not only our recruitment strategy (hospital-based recruitment of women from a tertiary Government of Zambia (GoZ) hospital), but also the current realities of ToP services in Zambia. Outside of GoZ hospitals, ToP can be provided by GoZ district clinics or third sector providers (e.g.: Marie Stopes International (MSI)). However, levels of ToP provision at GoZ clinics are very low for a variety of reasons (e.g.: no trained staff to provide MA, no MA drugs, no staff available willing to provide the service, and the lack of three doctors to sign off the decision). Service provision by third sector providers continues, and other providers continue to refer to the tertiary hospital, alongside limited provision of MA services themselves.

Individuals' stories show that girls' and women's trajectories to securing a termination can be complex and iterative. Individuals navigate complex private and public health systems as well as unqualified "providers" in order to achieve their pregnancy termination. Respondents frequently try multiple strategies in order to achieve pregnancy termination and many respondents attempt to induce abortion at home using medication or traditional methods (Figure 1).

\footnotetext{
${ }^{5}$ Not MA+/-MVA. Includes insertion of a foreign object, herbal medicine, and all other abortificants used by respondents to try to terminate a pregnancy
} 
Figure 1: Study participants' pregnancy termination trajectories

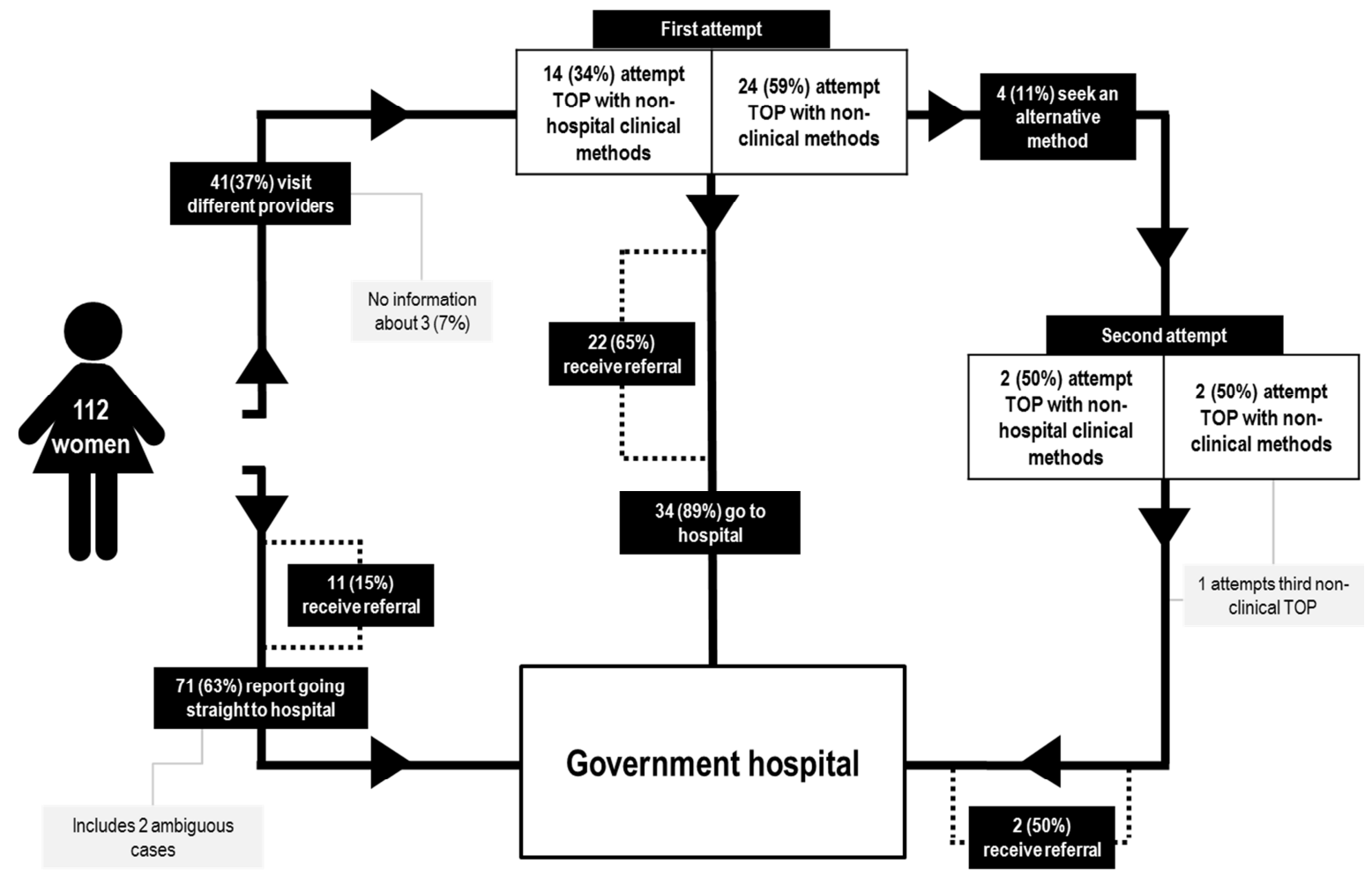

We present our analyses using four themes: the influence of advice; perceptions of risk; delays in care seeking and receipt and economic cost. All phenomena influence either the direction of trajectory (which typology a woman falls into), the complexity of the trajectory or the timing of the trajectory. Data, presented as anonymised vignettes and illustrative quotes, are drawn from a range of interviews to maximize for heterogeneity in sociodemographic characteristics, including: age, marital status, ethnic group, education, employment status, residence, in financial circumstances, and in clinical intervention and outcomes.

\section{THEME: The influence of advice}

The advice respondents sought and received, or did not seek, played significant role in shaping their trajectories (whether they were in typology 1, 2 or 3). Respondents' relationships with significant others - mothers, fathers, boyfriends, husbands, friends - and the quality of those relationships, the expectations of those relationships and the expectations held within those relationships, influenced who was told about their pregnancy, the decision to terminate it, how and where it was terminated and for some women, whether PAC at hospital was sought and when. It was typically others' knowledge of different service providers that shaped how women of typologies 1 \& 2 navigated care seeking.

Typology 1: 04023 is 33 years old and married. She has two children aged under 3 and lives in a township with her husband. They both run small businesses and just get by. Her pregnancy was unplanned and unexpected - they had been using condoms: 
"I called a friend, I explained my situation. // And she gave me a [study hospital] doctor's number and who I called."

Typology 1: 01006 is 16 years old and still at school. Her boyfriend left when she told him she was pregnant. She sought advice from her friends and then from her mother. Her mother consulted her father and aunt. It is her aunt and mother who accompany her to the hospital for a TOP:

"I just told my friend... I was scared to tell my mum [so] she said she was going to tell my mum for me.// My friends advised me to take some medicine like Panadol and all, but I said its better I tell my parents so that they advise. So when I told my mum, she advised me to go to the [local] clinic because taking medicine anyhow can damage my stomach... They did a scan on me and tested my blood... and I was told to go to [study hospital]."

Our data suggest that women who sought a termination directly from the government hospital were likely to have firstly, confided in someone about their pregnancy and secondly, confided in someone who either knew that the safe TOP was available at the hospital or were able to procure the direct phone number of a doctor who would provide the service for a fee. Women whose experiences are represented in typology 2 were typically influenced by more people.

Typology 2: 04009 is 17 years and works as a housemaid. She went for a pregnancy test at the local clinic with her sister. The pregnancy was unplanned but not unwanted by all. Her partner wanted to continue with the pregnancy while she reports getting mixed messages from "other people". Ultimately she didn't feel ready for a child. She attempts to terminate her pregnancy with tablets from a friend before attending a local clinic and then on her mother's advice, the study hospital for PAC:

"It was my friend, I had told her... She is my friend and I have known her for a long time now. I told her and I asked her if she knows medicine for aborting... She said there is someone I know but these things are dangerous you may die together with the child and I told her to just get for me... One was for drinking and the others 4 for inserting... [I] started paining around 23 hours... [I] went to [local] clinic. They referred me here. // I told mum at home [that I had taken the medicine], yes that's when she told me that we go to the clinic and she told me that I should have told her."

In the next case, the influence of significant others - in this case a step-mother and a school friend - are instrumental in the respondent's more complex journey (trajectory 3 ). This is an example of a young woman with very low levels of understanding of pregnancy or biological knowledge who was pregnant as a result of coerced sex by an older man.

01004 is 20 years old and finishing school. Following her parents' death she lives with her step-mother, her 'uncle' (step-mother's cousin) and her siblings and cousins, of whom she is oldest. She is sexually abused by her uncle. She felt unwell but was unaware she is pregnant until a neighbour tells her about a dream she has had and suggests she has a test. Her stepmother has also guessed she is pregnant and gives her a herbal drink to terminate it without discussing it: 
"At some time I felt dizzy and collapsed, then she made some herbal mix in a container... I didn't know but when I came back from school, she just game me and told me to drink then I drunk and only my stomach pained a lot... Then she made the mix again and forced me to drink. She said if I don't drink, she will beat me. Then I drunk and my stomach hurt again. Then after two days, I told my friend at school about it and she told me to go to [study hospital] and that I should explain then I can get help."

Her friend gave her money for transport to the hospital, while medical fees were waived by the hospital and a nurse paid for her transport home.

However, women of typology 3 were more likely to have not confided in anyone than women of typologies 1 and 2 . Respondents without friends or relatives they could confide in, and who did not know that a safe ToP was an option, or where to procure one, were more likely to try multiple (often escalating) methods. Particularly for married women who felt unable to either disclose the pregnancy or their decision to terminate it, the need to keep their conditions and actions a secret from their husband led to their being very alone in their care-seeking.

Typology 3: 03010 is 28 years old, married and daughter who is still very young. She did kept both her pregnancy and subsequent actions secret from her husband:

I: So when you knew that you were pregnant did you do anything to try and terminate it?

$R$ : I only had some Panadol... I only took two

She reports continuing to take her contraceptive pills, possibly hoping to precipitate a miscarriage. When the pregnancy continued, she escalated her attempts and went to an herbalist:

"I was given something to insert... I was given medicine, a stick... They inserted it themselves" Subsequently, her husband brought her to the hospital at night, as an emergency admission, after telling her husband that she had high blood pressure. She seems to have had no knowledge of the possibility of a safe( $r$ ) TOP.

\section{THEME: Perceptions of risk}

In women's decision-making about how to terminate a pregnancy the issue of mediating risks appeared, reflecting either the woman's own concerns or those concerns raised by people in whom she had confided; "one of my friends advised me to go to [tertiary hospital] instead of finding other measures" (Typology 1 04015). Avoidance or reduction of risk influenced women's selection of non-hospital MA versus non-clinical methods (Typology 2), and the selection of non-clinical method (Typology 3). However for some respondents the risks of harm were outweighed by the desire for a TOP.

Typology 2: 04011 is young and lives with her parents and brothers. She did not tell her family, but asked her friends for advice on how to terminate her pregnancy:

"They told me to try herbs from people. I told them I can't because I don't trust them, you can die".

On the advice of a different friend she looks for MA drugs, at first in her local drug store and then in the town: 
"So I had gone to a drug store near where I stay but they said that they don't do that. So my friend told me a friend of hers had done it with a certain medicine in a white box they are 5 in it, that's how she wrote for me on a paper and I went to buy in town."

When the MA causes her pain she tells her mother who took her to the local government clinic.

Contributing to respondents' decision-making was also perceptions of risk (and safety) of different sorts of providers. A clear narrative of trust and safety associated with Government providers emerged.

Typology 2: (01002) Admitted as an in-patient to the tertiary hospital for severe complications post-self-induced MA, followed by bleeding and then unknown injections at a private clinic:

"We decided to go to a government clinic because government hospitals we thought are much safer than the private clinics... I think it is a big hospital and they pay attention to patients. They do not want us to come back complaining so they really work hard."

For those respondents, particularly younger girls, navigating the complex and conflicting advice sought from others, perceptions of risk and safety - of weighing up the relative risks contributed substantially to their decision-making trajectories.

Typology 3: 03006 is young, at school and lives with her mother. Having decided to terminate her pregnancy, she found her friends discussing various non-clinical methods and selected the one she thought was safest:

"I found that there about of six of them there and they were busy chatting about methods that should be used for aborting the pregnancy... then I went home and decided to try whatever they were saying. That Cafemol really drugged me, felt like I was dying... I took twenty Cafemol tablets.//

They said a lot of things that people take to terminate the pregnancy... I heard that you can drink Coca-Cola with some tablets, some were saying you drink Jerico [hair gel], some said you should drink Cafemol. A lot was said even for using sticks.

I: So of all the stuff said, you chose to use Cafemol?

$R$ : Yes, felt that it safer."

In contrast, for some respondents, advice about the potentially harmful risks was outweighed by the respondent's need to terminate:

Typology 2: 04009, discussed above, sought information from her friend:

"She is my friend and I have known her for a long time now I told her and I asked her if she knows medicine for aborting...she said there is someone I know but these things are dangerous you may die together with the child and I told her to just get for me".

THEME: Delays in care seeking and receipt 
Delays to care-seeking, and sometimes its receipt, were common. The causes were many, and sometimes overlapping. But given the necessity for timeliness in either ToP or abortionrelated care-seeking, the implications of these delays for women's health are large. Delays linked to non-disclosure, particularly for Typologies 2 and 3, were common.

Typology 3: When the Cafemol taken by 03006 begins to cause her heavy bleeding, discharge and pain, she starts a lengthy process of care seeking:

"I was just feeling okay until after two weeks when I started wondering if I was rotting... That started worrying me a lot //

[I] went to [local clinic]. I explained to them something else because I was scared to tell them that I did something. They gave me prescriptions there but I did not buy the medicine because I knew that it was the wrong medicine. I went home and my mother asked me if I was given any medicine and I said yes. I tried to hide from my mother for few days but I [then] decided to tell her what was happening //

I: So from the clinic, you went home and what happened next?

R: I got sick that I could not move out of bed because of the pains... I then decided to tell my mother about what happened... She was very annoyed with me... I stayed for three days, very sick... On the third day, she called me from work and told me to meet her at some station so that she can take me to [a local clinic]

She was referred to the study hospital for sepsis.

For young girls, delays were often linked to a denial (to themselves) that they might be pregnant, a desire to ignore the problem and hope that it will go away.

Typology 3: 03006, met earlier:

$R \quad I$ just decided to just be and I was just observing but the days were going so fast. I then decided to do what I did [took 20 Cafemol tablets]

[As she became progressively unwell, she was unable to hide her condition from her mother]

$R$ Sometimes I could not even stand up straight. I then decided to tell my mother about what happened

I You told everything to your mother?

$R$ Yes, she was very annoyed with me and she said that she was going to leave me to rot because that is what I wanted. I stayed for three days, very sick and my mother just looking at me. On the third day she called me from work and told me to meet her at some station so that she can take me to [GoZ] clinic ...

$I \quad$ So the doctor referred you to [hospital]?

$R$ Yes ... If I had stayed at home hiding what happened, I would have died.

We did not interview people accompanying respondents in our study. This is one example where such additional information might be useful to understand the trajectory that was followed. It is possible that the mother was not simply "just looking" at her daughter and "leaving her to rot", but was trying to find out information as to what she should do, especially if she thought that her daughter might be charged with an illegal act. The mother worked full-time, so part of the delay in going to the GoZ clinic might have been due to her 
needing to find time off work. Given the route that they took, of going via GoZ clinic to get a referral letter, it is likely that this was in order to reduce the registration fee at the hospital.

Delays to care-seeking are not limited to those introduced by the healthcare system although these can be substantial and endemic - the unpredictability of daily life (possibly combined with an imperative to keep plans or actions secret) meant that delays to seeking care, even when symptoms were severe, occurred:

Typology 3: 02008 is A married woman with three children (the youngest of which she was still breastfeeding). When she found out she was pregnant, she continued to take her family planning pills, including taking all of the "red pills in the microgynon packet", hoping that it would help her miscarry. When this did not work, she took some other (unspecified) tablets. When she started bleeding heavily, however, she did not feel that she could afford not to open her market stall, so she delayed seeking care. On the day that she felt she could miss running her stall, it was raining heavily, making transport and travel too difficult. She eventually made it to the hospital to seek care. In her conversation with the interviewer, however, she maintained that she had not done anything to self-induce the pregnancy (although her medical notes suggested otherwise), perhaps not equating oral contraceptives or taking tablets with explicitly trying to self-induce:

$R$ I failed to do what other people do, like going to private clinics, because there I could be given some medicines and maybe when I reach home I may end up losing a lot of blood. So I was scared thst I could die and leave my children who would be alone suffering ...

$R \quad$ I had run out of ideas, so I just came here because I was scared of taking those herbal medicines

I did you take anything of such?

$R \quad$ No, I see how people die so I can't do that and that is why I came here

Further delays to her care were introduced as a result of the difficulties of navigating hospital systems and personnel:

$R$ I was told to come on the [date]. But then I forgot to book for that day but when I came I was given another booking and went to do a scan just to find out if anything went wrong in that I was bleeding earlier. You never know when you have a problem. So I was told to come on [date 2 weeks later] and so I was here yesterday

[When she arrived yesterday, she was sent away to return the next day.]

I OK so what happened with the doctor?

$R \quad$ well, he was difficult, he told me that it's not allowed by the Government

I OK, what else did the doctor say to you?

$R \quad$ He told me that he would help me, and that this should not happen again.

The respondent subsequently revealed, after extensive probing, that the doctor had charged her K200 for treatment. She was very reluctant to reveal what she had paid "Won' $t$ be taken to the police?".

The multiple combination of factors - acting in concert - lead to lots of small delays adding together to make a substantial (and potentially dangerous) delay to care seeking. The next 
example illustrates how a young girl - relatively economically powerless - experienced a series of delays in care seeking:

Typology 3: 04005 is 19 and lives with her parents. When she suspected that she might be pregnant she approached a doctor who is a neighbour, who helped her to do a pregnancy test. She drank lots of Coca-Cola in an attempt to self-induce. She then told her father that she had bad stomach pains. He took her to the neighbouring doctor, who, knowing that she was pregnant, gave her injections in her stomach. Substantial bleeding followed, and the respondent did not disclose to her father. The father then took her to another clinic, where they were given a referral letter to go to the hospital

$I \quad S o$ when you reached here at [hospital] he [father] knew by then that you are pregnant?

$R \quad$ No he didn't

I What was he telling you or asking you?

$R \quad$ He was asking

I What did you tell him?

$R \quad$ I just told him that it's my stomach

[At the hospital, treatment was further delayed because of her father's refusal to pay the registration fee.]

$R \quad$ When I came they tested me and the doctor said we have to pay K10, but he [father] refused to pay and the doctor said that, then come for cleaning [MVA] on Monday

I Who refused to pay?

R My dad

By contrast, Typology 1 in our sample rarely showed delay, beyond trying to get hold of a phone number of a doctor at the hospital. However, our data only include those women that managed to seek care. We cannot know the magnitude of cases that tried to seek a ToP, but were unable to secure the information to allow them to do this, and either became Typology 2 or 3 , or carried the pregnancy to term, or died trying to procure a termination.

\section{THEME: Economic costs}

In this sample of women who accessed hospital-based care, financial costs of seeking a TOP appear to influence the timing and complexity of trajectories, rather than the choice of TOP method and provider. The hospital served a large area and finding money for transport was a first hurdle. Unfortunately this study was not able to capture women who could not overcome it.

In order to increase efficiency in tertiary care, people are given economic incentives to access district clinics first: a referral from a satellite health centre reduces registration fee at a hospital from K80 to K10. For poorer women, knowledge of how to navigate the public sector health system made care affordable but also added an additional step in their trajectory to the hospital.

For other women, the clandestine cost of a TOP within the hospital could be significant, and introduce further delays: 
Typology 1: 02002 is 20 years old, from a poor family and stays with her mother's friend ('aunty') as a maid. She wanted a TOP because her widowed mother and her would not be able to care for a child. She told her aunty who called a hospital doctor for a TOP and they came to the hospital. However they were charged more than they expected and had to leave to find the outstanding balance. Only when returning a several weeks later was she given a medical abortion.

"I thought that... when we got here, everything would happen. That I would be admitted and given some medicine, but than that did not happen there and then, two weeks passed and I was told to comeback... Yes, I had come before, almost a month ago... About the money. We did not manage the money that we were told was not enough... We thought that maybe we would be charged 100, so that is the money we come with. So we gave him a 100 and had a balance of 200 [still to pay]. So that is how we went back.... We paid 200 [today], but it is not enough yet, we still have a balance."

In many of our cases, male involvement (boyfriend, husband, father, uncle) was instrumental in not only supporting the decision to terminate (and the preceding discussions), but also in procuring appointments and pharma or paying for treatment.

Typology 2: After agreeing with the boyfriend to terminate the pregnancy, they went together to a Government of Zambia (GoZ) Clinic where they were seen by a friend of her boyfriend's. She knew that her boyfriend had paid for this consultation, but did not know how much. She was given three tablets and told to insert them at home. After four days, the bleeding stopped. After two weeks she bled again and after another two weeks, clots started coming out. She went to visit her mother who noticed that she was pale and weak and that she had blood on her leg. She told her mother about what had happened and her mother took her to a private clinic where they gave her injections and the bleeding stopped. After two weeks, she had stomach pains, came to hospital, and was admitted for three nights. Scans revealed retained products in her uterus and severe infection. Interestingly, she said that when she goes home, she hopes to share her experience with her cousin.

Overall, women's (especially younger women's) knowledge of how much money had been paid for services, when the payment was made by a significant other (aunty, mother, husband, boyfriend) was very low. Although not dealt with in this paper, this finding has important methodological implications for studies of the individual-level costs involved in ToP care-seeking.

\section{RESEARCH LIMITATIONS}

The research is focused entirely on girls and women who have used government hospitalbased abortion-related services in Lusaka. Having an abortion, whether 'safe' or 'unsafe', is the result of an unwanted pregnancy, and the chain of events leading to (un)safe abortion is complex. Our sampling approach is pragmatic but it excludes undefined proportions of women who had an induced abortion with no complications elsewhere whether within or outside healthcare facilities; women who died as a result of unsafe abortion complications (who overall are likely to be poorer). 
This study represents a first step, but by no means the whole picture, in describing and understanding trajectories to pregnancy termination. Our recruitment strategy did not capture every woman or girl coming to the hospital for SA or abortion-related care treatment, those seeking care from a hospital doctor privately, for example, might not be entered into the hospital's record keeping system. Our interviewers were employed during the daytime on weekdays, therefore we missed women who came and were discharged at the weekends and at night. To try to mitigate this we changed our interviewers' shift patterns in order to have two team members in the ward from 6am to try to recruit women leaving hospital at dawn. At times this worked but often women came and went during the night. This may have produced a selection bias in our sample. Our recruitment strategy focused on women who had disclosed, directly or indirectly their intention of seeking induced abortion and therefore will have excluded women who did not disclose and who persisted in claiming to have had a spontaneous miscarriage.

Finally, doctors, ostensibly employed in the public sector but providing ToP and abortionrelated care services privately, featured largely in the narratives of women we interviewed. Women coming for ToP often had the phone number of a specific doctor or medic with whom they made a private arrangement. Some providers also charged high fees to women (up to 400 Kwacha or $£ 48$ ), far beyond the amounts set by the hospital (around 10-100 kwacha or $£ 1.20$ to $£ 12$ for standard procedures). This created an additional incentive to make sure their patients did not participate in our study. This problem of private work and private fees is not limited to abortion services at the study hospital, it is a wider problem. We tried various attempts to get providers 'on our side', introducing the project aims and objectives to them, assuring them of confidentiality. There is evidence that this worked to some extent as our recruitment did capture some of the patients who were charged the higher fees, however, it is likely that our low recruitment rates were at least partially attributable to this explanation.

\section{SUMMARY}

Despite the fact that termination of pregnancy has been legal since 1972 in Zambia, this research shows that levels of awareness about the legality of ToP and its provision in Zambia remain low among the general urban population. If morbidity and mortality associated with unsafe abortion are to be reduced, then not only does access to effective contraception need to be improved, but so does awareness of ToP services that exist. By comparing the experiences, pathways and trajectories of girls and women who have sought and received ToP and PAC services, our research is able to shed light on the complexities involved in navigating the health system (public, private, informal).

For girls and women who know that safe ToP services are available in the public health system, the process of obtaining a ToP can be relatively straightforward (variable payment of out-of-pocket fees notwithstanding). However, for those unaware of the provision of safe abortion services, the process to achieving a termination often begins with their immediate social networks. Abortion is highly stigmatised and the false perception that it is prohibited contributes to steering women towards clandestine methods. Our data show that it is essential to educate women and communities about their reproductive rights and options. 
The increasingly widespread availability of over-the-counter medical abortion drugs means that there is likely to be a reduction over time in the number of women seeking either TOP in hospital or PAC following induced abortion. We observed medical abortion kits to be readily available at pharmacies in Lusaka. MA bought from a pharmacist (and not administered by a health-care provider) may be expected to be safer and more effective than other methods attempted by women themselves, such as inserting objects or consuming herbal concoctions. Complications arising from home-based medical abortion, whereby a provider administers mifepristone at a clinic and the woman takes misoprostol at home, are rare and a systematic review has shown home-based MA to be as effective as clinic based MA (Ngo, Park et al. 2011). Globally, complications from unsafe abortion may be changing overtime as MA increases: less internal perforation and infection are expected overtime but evidence is lacking (Sedgh 2012). In other words, it is conceivable that if nonprovider administered home-based MA (MA from pharmacies) increased in Zambia there could have been a reduction in women attending hospital for TOP or PAC. It is possible that increasing numbers of women are using MA without medical supervision, encountering no complications and not seeking treatment at the study hospital. We do not, however, have evidence on whether there has been a rapid increase in the availability, sales or use of MA from pharmacies in Lusaka from previous years to 2013. Our evidence suggests that informal pharmacist and sole doctor practice provision of medical abortions should be better integrated into a mixed (public-private) healthcare provision strategy.

This study is the first in Zambia to explore the detail of trajectories to induced abortion and related abortion care in the urban public sector hospital to our knowledge. Even though ToP is legal in Zambia, girls and women take significant risks to terminate unwanted pregnancies. This finding echoes work done elsewhere; the 1971 MTP Act of India is still not fully implemented in practice (Banerjee, Andersen et al. 2012) (Banerjee and Andersen 2012, Banerjee, Andersen et al. 2012). There is an urgent need to address unmet need for contraception, strengthen family planning services and diffuse knowledge about ToP services. Although significant numbers of women reported MA - insufficient respondent knowledge about dose/type of MA drugs used (also found by Banerjee 2012 in India). We need to better understand the practical implications (including what is socially- and safetyacceptable) that underpin ToP method "choice". This means a need to understand not only the context but also individual-level constraints - making choices highly contingent.

By analysing the pathways that girls and women take to either achieving a ToP or abortionrelated care we can better focus attention on policy responses to increase accessibility to and quality of family planning and safe abortion services. In Zambia the need is for significant improvement in service delivery by trained mid-level providers to offer safe abortion services. 


\section{REFERENCES}

Adinma, E. D., J. I. B.-D. Adinma, C. Iwuoha, A. Akiode, E. Oji and O. Matthew (2012). "Knowledge and practices among medical abortion seekers in southeastern Nigeria." Southeast Asian Journal of Tropical Medicine and Public Health 43(2): 471-478.

Ahiadeke, C. (2001). "Incidence of induced abortion in southern Ghana." International Family Planning Perspectives: 96-108.

Ahmed, S., A. Islam, P. A. Khanum and K. Barkat e (1999). "Induced abortion: What's happening in rural Bangladesh." Reproductive Health Matters 7(14): 19-29.

Baboo, K. S., Y. Ahmed, S. Siziya and R. Bulaya (1994). "Characteristics of women terminating pregnancies at the UTH, Lusaka, Zambia." Central African Journal of Medicine 40(5): 110113.

Banerjee, S., K. L. Andersen, R. M. Buchanan and J. Warvadekar (2012). "Woman-centered research on access to safe abortion services and implications for behavioural change communication interventions: a cross-sectional study of women in Bihar and Jharkhand, India." BMC Public Health 12: 175.

Banerjee, S. K. and K. Andersen (2012). "Exploring the Pathways of Unsafe Abortion in Madya Pradesh, India." Global Public Health Journal Forthcoming.

Banerjee, S. K., K. L. Andersen and J. Warvadekar (2012). "Pathways and consequences of unsafe abortion: A comparison among women with complications after induced and spontaneous abortions in Madya Pradesh, India." International Journal of Gynecology and Obstetrics 118(Suppl 2): S113-S120.

Castle, M., R. Likwa and M. Whittaker (1990). "Observations on abortion in Zambia." Studies in Family Planning 21(4): 231-235.

Central Statistics Office, Ministry of Health, Tropical Diseases Research Centre, University of Zambia and M. I. Inc (2009). Zambia Demographic and Health Survey 2007. Calverton, Maryland, USA, CSO and Macro International Inc.

Chakwe, M. (2013). Unsafe abortion remains a challenge - Dr Macha. The Post Newspapers. Lusaka, Zambia.

Concerned (2014). Abortions again. The Post Online.

Dahlback, E., M. Maimbolwa, L. Kasonka, S. Bergstrom and A. Ransjo-Arvidson (2007).

"Unsafe Induced Abortions Among Adolescent Girls in Lusaka." Health Care for Women International 28(7): 654-676.

Dixon-Woods, M. (2011). "Using framework-based synthesis for conducting reviews of qualitative studies." BMC Medicine 9(1): 39.

Gale, N., G. Heath, E. Cameron, S. Rashid and S. Redwood (2013). "Using the framework method for the analysis of qualitative data in multi-disciplinary health research." BMC Medical Research Methodology 13(1): 117.

Ganatra, B., T. O., H. B. Johnston, B. R. Johnson, A. M. Gülmezoglu and M. Temmerman (2014). "From concept to measurement: operationalizing WHO's definition of unsafe abortion." Bulletin of the World Health Organization 92(3): 153-228.

Grimes, D. A., J. Benson, S. Singh, M. Romero, B. Ganatra, F. E. Okonofua and I. H. Shah (2006). "Unsafe abortion: the preventable pandemic." The Lancet 368(9550): 1908-1919. GRZ, G. o. t. R. o. Z. (1972). Termination of Pregnancy Act, Laws of Zambia, Chapter 304. Constitution of Zambia. Lusaka, Government of Zambia.

GRZ, G. o. t. R. o. Z. (2009). Standards and Guidelines for reducing unsafe abortion morbidity and mortality in Zambia. M. o. Health. Lusaka, Government Printers. 
Guttmacher Institute (2012). Facts on Abortion in Africa. In Brief. New York, Guttmacher Institute.

Kalunga, K. (2012). Rephrase conception, submits youth body. Times of Zambia.

Kapoor, S. K., A. V. Raman, K. S. Sachdeva and S. Satyanarayana (2012). "How Did the TB Patients Reach DOTS Services in Delhi? A Study of Patient Treatment Seeking Behavior." PLOS ONE 7(8): e42458.

Kaseba, C., D. Phiri, C. Camlin, H. Sanglivi, T. Smith, P. Chibuye and M. Folsom (1998). The situation of postabortion care in Zambia. Research Triangle Park, NC, Research Triangle Institute.

Kinaro, J., T. Ali, R. Schlangen and J. Mack (2009). "Unsafe Abortion and Abortion Care in Khartoum, Sudan." Reproductive Health Matters 17(34): 71-77.

Koster-Oyekan, W. (1998). "Why resort to illegal abortion in Zambia? Findings of a community-based study in Western province." Social Science \& Medicine 46(10): 1303-1312. Likwa, R. N. (2009). Abortion statistics in Zambia: research in brief. Lusaka, Zambia. Lusaka, Zambia, Department of Community Medicine, School of Medicine, University of Zambia. Likwa, R. N., A. E. Biddlecom and H. Hall (2009). "Unsafe Abortion in Zambia: In Brief." Guttmacher Institute 2009 Series(3).

Likwa, R. N. and M. Wittaker (1996). "The characteristics of women presenting for abortion and complication of illegal abortions at the University Teaching Hospital, Lusaka, Zambia: An exploratory study." African Journal of Fertility, Sexuality and Reproductive Health 1(1): 42 49.

Migiro, K. (2013). Maputo Protocol: forcing abortion on Africa or securing women's rights? Thomson Reuters Foundation. Nairobi.

Mitchell, E. M., A. Kwizera, M. Usta and H. Gebreselassie (2010). "Choosing early pregnancy termination methods in Urban Mozambique." Soc Sci Med 71(1): 62-70.

$\mathrm{MoH}$ (2009). Standards and guidelines for reducing unsafe abortion morbidity and mortality in Zambia. Lusaka, Ministry of Health: 1-64.

Mtonga, V. and M. Ndhlovu (2001). "Midwives' role in management of elective abortion and post-abortion care: Zambian countryu report. Paper presented at "Expanding access:

advancing the roles of midlevel providers in mentrual regulation and elective abortion care", South Africa, December 2-6, 2001."

Ngo, T. D., M. H. Park, H. Shakur and C. Free (2011). "Comparative effectiveness, safety and acceptability of medical abortion at home and in a clinic: a systematic review." Bulletin of the World Health Organization 89(5): 360-370.

Pillai, V. K. and D. L. Yates (1993). "Teenage sexual activity in Zambia: the need for a sex education policy." Journal of Biosocial Science 25(3): 411-414.

Rihoux and Grimm (2006). Innovative Comparative Methods for Policy Analysis: Beyond the Qualitative - Quantitative Divide. New York, Springer.

Ritchie, J. and J. Lewis (2003). Qualitative research practice : a guide for social science students and researchers. London, Sage Publications.

Rossier, C. and et al. (2006). "Estimating clandestine abortion with the confidants methods results from IOuagadougou, Burkina Faso." Social Science \& Medicine 62: 254-266.

Schwandt, H. M., A. A. Creanga, R. M. Adanu, K. A. Danso, T. Agbenyega and M. J. Hindin (2013). "Pathways To Unsafe Abortion In Ghana: The Role Of Male Partners, Women, And Health Care Providers." Contraception.

Sims, P. (1996). "Abortion as a public health problem in Zambia." Journal of Public Health Medicine 18(2): 232-233. 
Singh, S., T. Fetters, H. Gebreselassie, A. Abdella, Y. Gebrehiwot, S. Kumbi and S. Audam (2010). "The estimated incidence of induced abortion in Ethiopia, 2008." International Perspectives on Sexual and Reproductive Health: 16-25.

TCDZC, T. C. o. D. t. Z. C. (2012). First Draft Constitution of the Republic of Zambia. T. C. o. D. t. Z. C. The Secretariat. Lusaka, GRZ.

UN and CEDAW (2011). Concluding observations of the Committee on the Elimination of Discrimination against Women Zambia. 49th session. C. o. t. E. o. D. a. Women.

UNTC. (2013). "United Nation Treaty Collection. Chapter IV Human Rights. 8. Convention on the Elimination of All Forms of Discrimination against Women." Retrieved 16 October, 2013, from http://treaties.un.org/Pages/ViewDetails.aspx?src=TREATY\&mtdsg no=IV8\&chapter=4\&lang=en.

Ward, D. J., C. Furber, S. Tierney and V. Swallow (2013). "Using Framework Analysis in nursing research: a worked example." Journal of Advanced Nursing 69(11): 2423-2431. Webb, D. (2000). "Attitudes to "Kaponya Mafumo": the terminators of pregnancy in urban Zambia." Health Policy and Planning 15(2): 186-193.

WHO (2012). Safe Abortion: Technical and Policy Guidance for Health Systems. Geneva, World Health Organization.

WHO, UNICEF, UNFPA, The World Bank and United Nations Population Division Maternal Mortality Estimation Inter-Agency Group (2013). Maternal mortality in 1990-2013: Zambia. Geneva, World Health Organization.

Zambian Watchdog (2012). Emmanuel Mwamba bans Marie Stopes International from performing abortions. Zambian Watchdog. Lusaka. 